\title{
A Rare Case of Adrenocortical Carcinoma
}

\author{
AFSANA F $^{\mathrm{a}}$, LATIF ZA $^{\mathrm{b}}$, PATHAN MF $^{\mathrm{b}}$
}

\begin{abstract}
A 15 year old girl was admitted with absence of menstruation and increase growth of facial and body hair for two years along with change of voice for six months. With these complaint, tablet progesterone was advised but there was no withdrawal bleeding. On examination she had hirsuitism. She had normal female secondary sex characteristics with mild clitoromegaly. Her investigations revealed hyperandrogenemia with normal level of other adrenal hormones. Imaging revealed left adrenal mass. Left
\end{abstract}

\section{Introduction}

Adrenocortical carcinoma is uncommon and extremely rare in children. The majority of cases present with a combination of clinical features of Cushing's syndrome and hyperandrogenism with or without pulmonary metastasis. ${ }^{1-}$ ${ }^{3}$ Hypertension may not be always present. ${ }^{4}$ Diagnosis depends on clinical manifestations, demonstration of elevated hormone levels and localization of tumour(s). Surgical removal of tumor often normalizes the features but medical management is sometimes required. ${ }^{1,3}$ adrenalectomy done and histopathology revealed malignant tumor of Zona reticularis. Adrenocortical carcinoma is a rare tumor and only limited information is available about its natural history and the effects of therapy. The case is a rare androgen producing malignant tumor of adrenal having an earlier age of presentation.

Key Words: Adrenocortical Carcinoma; Androgen Producing tumour.

(Birdem Med J 2013; 3(2): 110-112)

\section{Case Report}

A 15 years girl was admitted with absence of menstruation and increase growth of facial and body hair for 2 years along with change of voice for 6 months. She attained her menarche 3 years back at the age of 12 years. Her menstrual cycle was irregular since beginning. She had only 3 cycles in 1 st year after menarche. Later on she became amenorrhic. She visited a gynecologist who advised tab. progesterone but there was no withdrawal

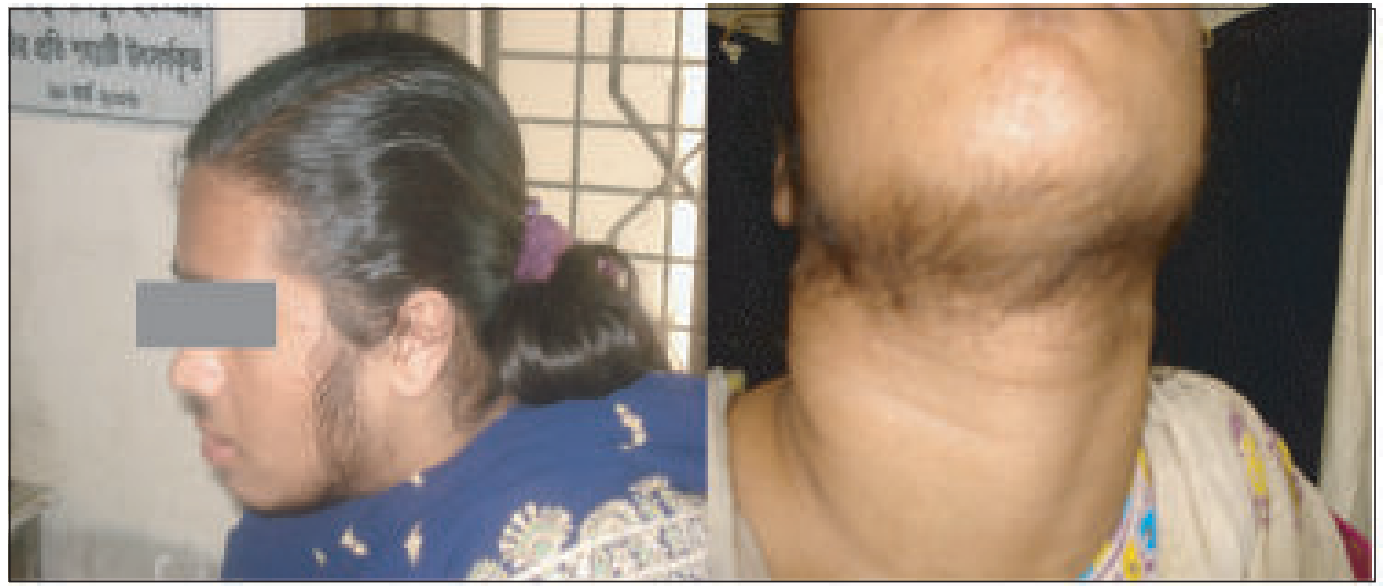

Fig.-1: Hirsuitism and frontal balding in the study case

a. Dr. Faria Afsana, MD (Endocrinology), Registrar, Endocrinology, BIRDEM, Dhaka, Bangladesh

b. Prof. Zafar Ahmed Latif, FCPS (Medicine), Prof. Md. Faruque Pathan, MD (Endocrinology), Department of Endocrinology, BIRDEM, Dhaka, Bangladesh

Address of Corresponding : Dr. Faria Afsana, MD (Endocrinology), Registrar, Endocrinology, BIRDEM, Dhaka, Bangladesh, E-mail: fariaafsana@yahoo.com

Received: 02 July, 2012

Accepted: 09 July, 2013 bleeding. After getting high S. testosterone level (4.0 $\mathrm{pmol} / \mathrm{l}$ ) and left adrenal mass in USG, she was referred to Endocrinology unit for evaluation and management. She did not have any history of severe illness in her childhood. She was delivered by normal vaginal delivery and her perinatal period was uneventful. She is nondiabetic and normotensive. She did not have any significant positive family history. 


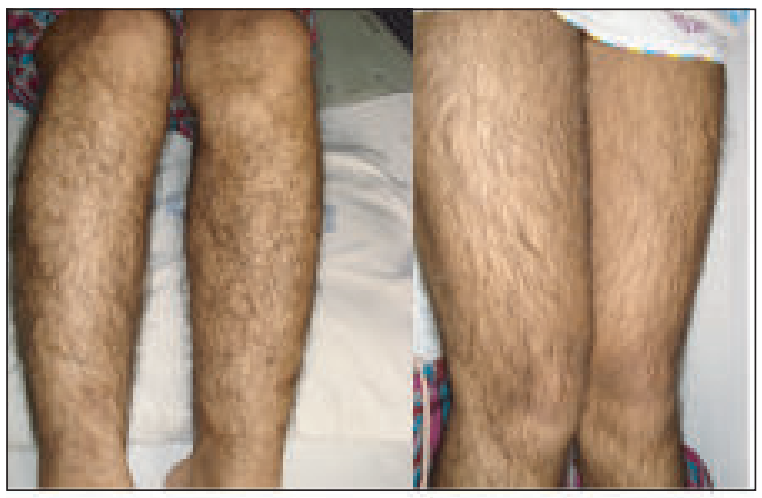

Fig.-2: Increase growth of hair in lower limb of the study case.

On general examination hirsuitism was present. Her breast development was normal, external genitalia and pubic hair is of normal female type. There was mild clitoromegaly.

Subsequent laboratory investigations showed normal routine tests reports with normal X-ray chest and E.C.G. Hormone levels were: S.Testosterone 4.19 pmol/1(0.20.9), DHEA-9.8 pmol/1 (1.3-9.8), 17 hydroxyprogesterone level 1.39 (<80 ng/dL), TSH -3.69 $\mu$ IU/1 (0.4-5.03), FT4$16.16 \mathrm{ng} / \mathrm{ml}$ (9.0-23.0), Basal Cortisol-550 ng/ml.

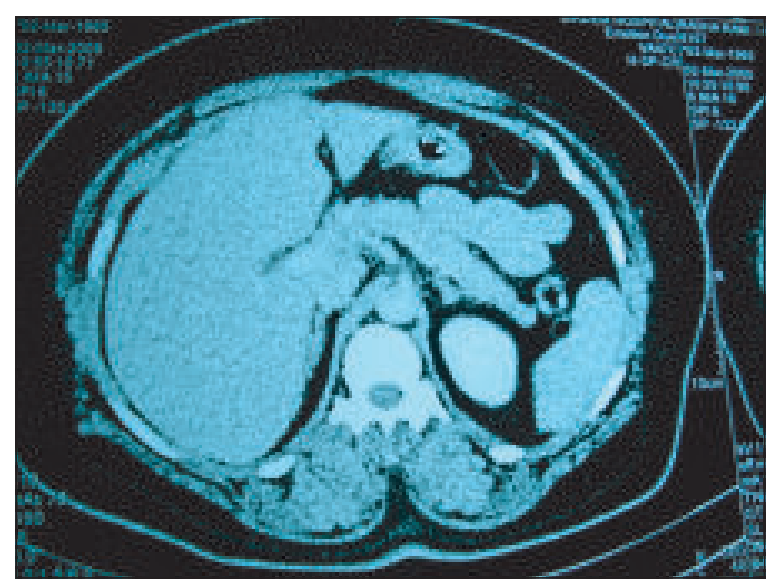

Fig.-3: Contrast CT scan of abdomen of the study case showing contrast enhanced left adrenal mass

CT scan of Abdomen revealed large well defined low density mass measuring about $7.5 \times 5.5 \mathrm{~cm}$ having calcification in left adrenal region in the upper pole of left kidney and medial aspect of spleen. The lesion showed homogenous enhancement after I/V contrast.

Left adrenalectomy was done by sub costal incision under epidural anesthesia. In laparotomy it was found

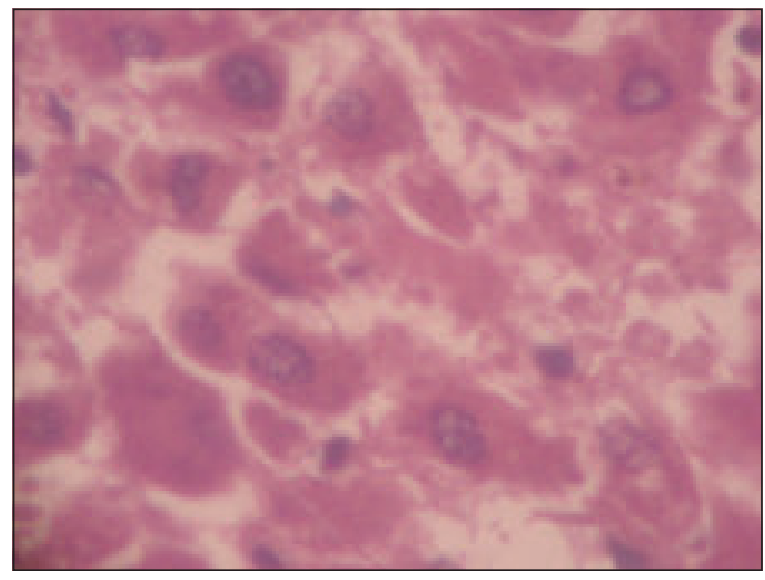

Fig.-4: Histopathology of the operated adrenal of the study case

that left adrenal gland was enlarged $7 \mathrm{~cm} \times 6 \mathrm{~cm}$, firm and there was no adhesion to adjacent structures and any peritoneal seedling or regional lymphadenopathy. Histopathology revealed left adrenocortical carcinoma.

One month after surgery her S.testosterone level was $0.15 \mathrm{pmol} / 1$, LH- $2.28 \mathrm{mIU} / 1$, FSH- $2.11 \mathrm{mIU} / 1$. Her menstruation started spontaneously one month following surgery. She noticed gradual reduction of body hairs. She was discharged from hospital with advice to come for regular follow up.

\section{Discussion}

Adrenocortical carcinoma is a rare tumor and only limited information is available about its natural history and the effects of therapy. Radical surgical excision is the treatment of choice for patients with localized malignancy and remains the only method by which longterm disease-free survival may be achieved. Overall 5years survival after resection of tumor is approximately $40 \%$. Approximately $60 \%$ of patients present with symptoms related to excessive hormone secretion but hormone testing reveals that $60 \%$ to $80 \%$ of tumors are functioning. 5,6 The most common sites of metastases are the peritoneum, lung, liver, and bone. Palliation of metastatic functioning tumors may be achieved by resection of both the primary tumor and metastatic lesions. Unresectable or widely disseminated tumors may be palliated by antihormonal therapy with mitotane, systemic chemotherapy, or (for localized lesions) radiation therapy. Retrospective studies have identified two 
important prognostic factors: completeness of resection and stage of disease. Patients without evidence of invasion into local tissues or spread to lymph nodes have an improved prognosis. ${ }^{7}$

Because of the rarity of adrenocortical carcinoma, after operation survival rate and the prognosis is not well known. The French Association of Endocrine Surgery evaluated these factors in all patients treated during a 12 -year period by its members. ${ }^{8}$ Multivariate analysis showed that better prognosis occurred in patients younger than 35 years of age $(p=0.01)$ and in patients with androgen-secreting tumors, precursor-secreting tumors, or nonsecreting tumors $(\mathrm{p}=0.003)$. Mitotane improved the survival rate only in patients with metastases who received it after operation. This is a case is a rare endocrine case in perspective of its incidence and its age of presentation.

\section{References}

1. Jaruratanasirikul S, Patarapinyokul S, Mitranun W. Androgen-producing adrenocortical carcinoma: report of 3 cases with different clinical presentations. J Med Assoc Thai 2012;95(6):816-20.
2. Vieira H, Brain C. Cushing syndrome associated with an adrenal tumour. BMJ Case Rep 2012 Aug 27;2012. pii: bcr2012006685. doi: 10.1136/bcr-2012-006685.

3. Brutsaert EF, Sasano H, Unger P, Beasley MB, Golden BK, Inabnet WB 3rd, et al. Adrenal cortical carcinoma with late pulmonary metastases causing clinicical Cushing's syndrome: case report with immunohistochemical analysis of steriodogenic enzyme production. Endocr Pract 2012;18(6):138-43.

4. Song MS, Seo SW, Bae SB, Kim YJ, Kim SJ. Aldosteroneproducing adrenocortical carcinoma without hypertension. Korean J Intern Med 2012;27(2):221-23.

5. Norton JA. Adrenal tumors. In: DeVita VT Jr, Hellman S, Rosenberg SA, eds. Cancer: Principles and Practice of Oncology. 7th ed. Philadelphia, Pa: Lippincott Williams \& Wilkins; 2005: p 1528-39.

6. Icard P, Chapuis Y, Andreassian B, et al. Adrenocortical carcinoma in surgically treated patients: a retrospective study on 156 cases by the French Association of Endocrine Surgery. Surgery 1992; 112 (6): 972-9

7. Luton JP, Cerdas S, Billaud L, et al. Clinical features of adrenocortical carcinoma, prognostic factors, and the effect of mitotane therapy. N Engl J Med 1990; 322 (17): 1195-1201.

8. Lee JE, Berger DH, el-Naggar AK, et al. Surgical management, DNA content and patient survival in adrenal cortical carcinoma. Surgery 1995; 118 (6): 1090-98. 